\title{
The Role of Attrition and Solids Recovery in a Chemical Looping Combustion Process
}

\author{
M. Kramp, A. Thon, E.-U. Hartge, S. Heinrich and J. Werther* \\ Institute of Solids Process Engineering and Particle Technology, Hamburg University of Technology, 21071 Hamburg - Germany \\ e-mail: m.kramp@tuhh.de - a.thon@tuhh.de - hartge@tuhh.de - stefan.heinrich@tuhh.de -werther@tuhh.de \\ * Corresponding author
}

\begin{abstract}
Résumé - Effet de l'attrition et de la récupération des particules dans le procédé de combustion en boucle chimique - Le présent travail propose un modèle de simulation en continu du procédé de combustion en boucle chimique constitué de deux lits fluidisés interconnectés. Les simulations ont été conduites à deux échelles $50 \mathrm{kWth}$ correspondant à une installation pilote et $100 \mathrm{MWth}$ correspondant à une installation industrielle. Un modèle décrivant l'attrition, établi à partir d'expériences conduites à petite échelle au laboratoire, a été utilisé pour étudier l'évolution de la granulométrie et des pertes aux cyclones des particules transportant l'oxygène dans le procédé. Des débits de circulation de particules réalistes sont calculés par simulations et les pertes aux cyclones peuvent être quantifiées. Rapportées à la puissance de l'installation, les pertes en particules aux cyclones sont plus élevées à l'échelle industrielle qu'à l'échelle pilote. Il a également été observé qu'à l'échelle industrielle on obtient une conversion plus faible de la charge gazeuse dans le réacteur fioul à cause du by-pass induit par les bulles dans ce réacteur. Sur la base des simulations, il n'est donc pas garanti que les performances soient identiques à l'échelle pilote et à l'échelle industrielle à cause de l'hydrodynamique. Avec le simulateur, il est également possible d'étudier l'impact du système de récupération des particules dans les effluents gazeux sur les pertes. La répartition des pertes entre le réacteur air et le réacteur fioul est étudiée avec différentes configurations. Il est, par exemple, montré que l'ajout d'un deuxième étage de cyclone en sortie du réacteur air permet de réduire significativement les pertes en matériau transporteur d'oxygène.
\end{abstract}

Abstract - The Role of Attrition and Solids Recovery in a Chemical Looping Combustion Process In the present work, the steady-state behavior of a Chemical Looping Combustion process of interconnected fluidized bed reactors is simulated. The simulations have been carried out in two different scales, $50 \mathrm{~kW}_{\text {th }}$ and $100 \mathrm{MW}$ th. Attrition model derived from small scale laboratory experiments has been employed for the prediction of the process behavior in terms of attrition and Oxygen Carrier loss. Information on Oxygen Carrier characteristics and reaction kinetics were taken from literature. Realistic circulation mass flows of Oxygen Carrier particles are obtained and Oxygen Carrier losses are quantified. The large scale process looses significantly more Oxygen Carrier than the small scale process based on the same amount of thermal energy produced. Incomplete conversion in the air reactor could be identified as a critical point. Another issue is the fuel gas bypassing the Oxygen Carrier particles through bubbles in the large scale process which leads to lowered fuel conversions. The simulations indicate that a similar performance of a pilot scale and a large scale process is not guaranteed due to the scale-up effect on fluid dynamics. Furthermore, the simulations allow an assessment of the influence of the quality of the solids recovery system on the Oxygen Carrier loss. The distribution of the losses between possible origins is investigated and different changes in the solids recovery system are discussed regarding their potential to decrease the Oxygen Carrier loss. For example, the addition of a second-stage cyclone after the air reactor of the large scale process reduces the Oxygen Carrier loss significantly. 


\section{NOTATION}

$a \quad$ Decay constant $\left(\mathrm{m}^{-1}\right)$

$a_{\text {transfer }}$ Transfer area $\left(\mathrm{m}^{-1}\right)$

$A_{t} \quad$ Cross sectional area of cyclone inlet $\left(\mathrm{m}^{2}\right)$

$b \quad$ Stoichiometric coefficient (-)

$c_{v} \quad$ Solids volume concentration (-)

$c_{v s} \quad$ Solids volume concentration of suspension phase (-)

$c_{v, i} \quad$ Solids volume concentration of particle size class $i(-)$

$c_{v \infty, i} \quad$ Solids volume concentration of particle size class $i$ above TDH (-)

$c_{v, m f} \quad$ Solids volume concentration at minimum fluidization condition (-)

$C \quad$ Local reactant gas concentration $\left(\mathrm{mol} \mathrm{m}^{-3}\right)$

$C_{b} \quad$ Local reactant concentration in bubbles $\left(\mathrm{mol} \mathrm{m}^{-3}\right)$

$C_{s} \quad$ Local reactant concentration in suspension $\left(\mathrm{mol} \mathrm{m} \mathrm{m}^{-3}\right)$

$d_{b} \quad$ Bubble diameter $(\mathrm{m})$

$d_{b 0} \quad$ Initial bubble diameter (m)

$d_{g} \quad$ Grain diameter $(\mathrm{m})$

$\bar{d}_{p, i} \quad$ Mean particle size of interval $i(\mathrm{~m})$

$d_{p, s} \quad$ Sauter mean diameter $(\mathrm{m})$

$d_{\text {or }} \quad$ Diameter of orifice $(\mathrm{m})$

$d_{t} \quad$ Bed diameter $(\mathrm{m})$

$D_{g} \quad$ Molar binary diffusion coefficient $\left(\mathrm{m}^{2} \mathrm{~s}^{-1}\right)$

$E_{a} \quad$ Activation energy $\left(\mathrm{J} \mathrm{mol}^{-1}\right)$

$g \quad$ Gravitational acceleration $\left(\mathrm{m} \mathrm{s}^{-2}\right)$

$G_{s \infty, i} \quad$ Solids flux above TDH for particles in size class $i$ $\left(\mathrm{kg} \mathrm{m}^{-2} \mathrm{~s}^{-1}\right)$

$k \quad$ Reaction rate constant $\left(\mathrm{mol}^{1-n} \mathrm{~m}^{3 n-2} \mathrm{~s}^{-1}\right)$

$k_{0} \quad$ Pre-exponential factor $\left(\mathrm{mol}^{1-n} \mathrm{~m}^{3 n-2} \mathrm{~s}^{-1}\right)$

$k_{g} \quad$ Inter-phase diffusion rate coefficient $\left(\mathrm{m} \mathrm{s}^{-1}\right)$

$k_{b} \quad$ Material specific bubble attrition constant $\left(\mathrm{m}^{-1}\right)$

$k_{c} \quad$ Material specific cyclone attrition constant $\left(\mathrm{s}^{2} \mathrm{~m}^{-3}\right)$

$k_{j} \quad$ Material specific grid jet attrition constant $\left(\mathrm{s}^{2} \mathrm{~m}^{-3}\right)$

$K_{i \infty}^{*} \quad$ Elutriation constant $\left(\mathrm{kg} \mathrm{m}^{-2} \mathrm{~s}^{-1}\right)$

$K_{Q} \quad$ Rate of convective inter-phase mass transfer $\left(\mathrm{s}^{-1}\right)$

$m_{\text {bed }} \quad$ Bed mass (kg)

$\dot{m}_{i} \quad$ Mass flow in size interval $i\left(\mathrm{~kg} \mathrm{~s}^{-1}\right)$

$\dot{m}_{o x} \quad$ Mass flow of solids in oxidized state $\left(\mathrm{kg} \mathrm{s}^{-1}\right)$

$\dot{m}_{\text {red }} \quad$ Mass flow of solids in reduced state $\left(\mathrm{kg} \mathrm{s}^{-1}\right)$

$n \quad$ Reaction order (-)

$n_{0} \quad$ Number of orifices (-)

$P \quad$ Pressure $\left(\mathrm{kg} \mathrm{m}^{-2}\right)$

$r_{g} \quad$ Gas reaction rate $\left(\mathrm{mol} \mathrm{m}^{-3} \mathrm{~s}^{-1}\right)$

$r_{s} \quad$ Solids reaction rate $\left(\mathrm{mol} \mathrm{m}^{-3} \mathrm{~s}^{-1}\right)$

$R \quad$ Gas constant $\left(\mathrm{J} \mathrm{mol}^{-1} \mathrm{~K}^{-1}\right)$

$t \quad$ Time (s)

$u \quad$ Superficial gas velocity $\left(\mathrm{m} \mathrm{s}^{-1}\right)$

$u_{b} \quad$ Rise velocity of bubbles $\left(\mathrm{m} \mathrm{s}^{-1}\right)$ $u_{m f} \quad$ Minimum fluidization velocity $\left(\mathrm{m} \mathrm{s}^{-1}\right)$

$u_{o r} \quad$ Gas velocity in orifice $\left(\mathrm{m} \mathrm{s}^{-1}\right)$

$u_{t, i} \quad$ Terminal settling velocity of particles in size class $i$ $\left(\mathrm{m} \mathrm{s}^{-1}\right)$

$u_{0} \quad$ Superficial gas velocity at gas inlet $\left(\mathrm{m} \mathrm{s}^{-1}\right)$

$\dot{V}_{b} \quad$ Visible bubble flow rate $\left(\mathrm{m} \mathrm{s}^{-1}\right)$

$\dot{V}_{0} \quad$ Volume flow through single orifice $\left(\mathrm{m}^{3} \mathrm{~s}^{-1}\right)$

$X_{s} \quad$ Solids conversion (-)

$z \quad$ Height above gas distributor (m)

$\varepsilon_{b} \quad$ Bubble volume fraction (-)

$\vartheta \quad$ Parameter describing influence of bed diameter (-)

$\lambda \quad$ Mean life time of a bubble (s)

$\mu \quad$ Solids load at cyclone inlet (-)

$v \quad$ Kinematic viscosity $\left(\mathrm{m}^{2} \mathrm{~s}^{-1}\right)$

$v_{i} \quad$ Stoichiometric coefficients (-)

$\rho_{f} \quad$ Gas density $\left(\mathrm{kg} \mathrm{m}^{-3}\right)$

$\rho_{m} \quad$ Molar density of reactant $\left(\mathrm{mol} \mathrm{m}^{-3}\right)$

$\rho_{s} \quad$ Apparent solid density $\left(\mathrm{kg} \mathrm{m}^{-3}\right)$

$\tau \quad$ Time necessary for full conversion of particle (s)

$\varphi \quad$ Correlation factor (-)

$\Delta Q_{3, i} \quad$ Mass fraction in size interval $i(-)$

\section{Abbreviations}

AR Air Reactor

BFB Bubbling Fluidized Bed

CFB Circulating Fluidized Bed

CLC Chemical Looping Combustion

FR Fuel Reactor

OC Oxygen Carrier

PSD Particle Size Distribution

TDH Transport Disengaging Height

\section{INTRODUCTION}

Chemical Looping Combustion (CLC) is a carbon capture and storage technology that can be employed to obtain a stream of almost pure $\mathrm{CO}_{2}$ at the end of a power plant fired with fossil fuels. The $\mathrm{CO}_{2}$ rich stream can be sent to sequestration in order to prevent the greenhouse gas $\mathrm{CO}_{2}$ from being emitted to the atmosphere. In CLC the mixing of the combustion products $\mathrm{CO}_{2}$ and $\mathrm{H}_{2} \mathrm{O}$ with air nitrogen is prevented. Oxygen Carrier (OC) particles are oxidized at high temperatures by air oxygen. After oxidation the particles are separated from the gas flow and subjected to reducing gases like methane. The Oxygen Carrier particles will provide the oxygen necessary for the combustion reaction of the reducing gases. Reduced Oxygen Carrier particles are again oxidized with air. A continuous operation of Chemical Looping Combustion is $e . g$. possible in a system of two coupled 
fluidized bed reactors [1]. The feasibility of a Chemical Looping Combustion process is dependent on the process costs, which will be greatly influenced by the Oxygen Carriers involved. Oxygen Carrier particles can be categorized into particles of natural origin (e.g. iron ores, ilmenite...) and synthetically manufactured particles. Many natural Oxygen Carriers suffer from agglomeration that will lead to defluidization [2] or mechanical instability due to the reactions [3]. The reaction rate depends on the surface area available for the heterogeneous reaction. Natural Oxygen Carriers usually are not as porous as synthetic carriers, even though activation was reported in literature $[4,5]$. A major concern in Chemical Looping Combustion is the mechanic stability of the Oxygen Carrier particles since the particles will be repeatedly subjected to stresses in a process of coupled fluidized beds. The mechanical stability of the Oxygen Carrier particles is therefore a key to a successful CLC process. These demands towards Oxygen Carrier particles favor the use of synthetic OC particles. On the other hand are synthetic Oxygen Carriers more expensive and thus it is of great importance to minimize the loss of valuable Oxygen Carrier particles. In either case it is desirable to have attrition resistant Oxygen Carrier particles and the loss through the gas-solids separation devices (e.g. cyclones) have to be minimized.

The aim of this investigation is to study the Chemical Looping Combustion process from the particle technology point of view. Simulations have been carried out to study the circulation mass flow between the interconnected fluidized bed reactors as well as the respective particle size distributions and Oxygen Carrier (OC) losses. The influence of OC particle attrition on the process performance is investigated and possible improvements of the solids recovery are studied. Simulations have been carried out in two scales: pilot scale and an up-scale to a $100 \mathrm{MW}_{\text {th }}$ process.

\section{THEORY}

\subsection{Fluid Dynamics in the Fluidized Beds}

The fluidized bed reactors are divided into two zones, a solids rich bottom zone and an upper dilute zone. The gas concentration profile is calculated in dependency of the height of the reactor as it is assumed to rise in plug flow. The solids within the reactor on the other hand are assumed to be perfectly mixed.

\subsubsection{Description of the Bottom Zone}

The bottom zone is described by a semi-empirical approach, distinguishing between a suspension phase and a solids free bubble phase as shown in Figure 1. The gas passing through the suspension phase is assumed to rise with $u_{m f}$. Thus the excess gas is rising in the bubble phase.

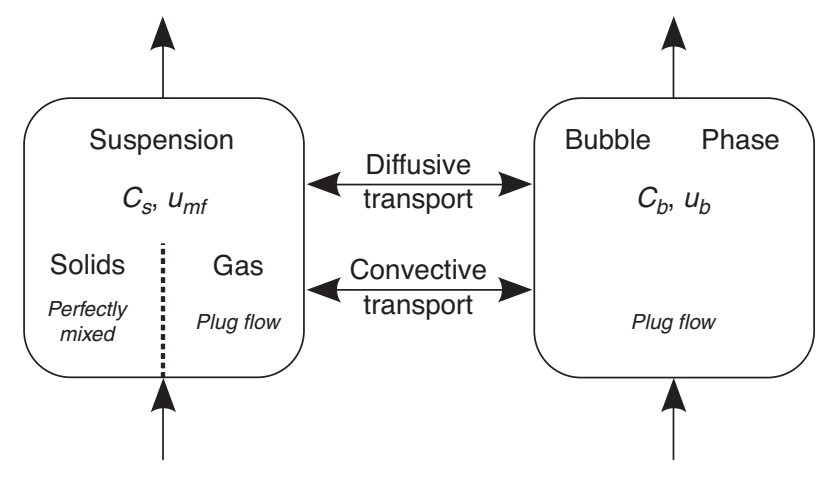

Figure 1

Sketch of the model for the bottom zone.

The fluid dynamics are calculated according to Werther and Wein [6]. The solids volume concentration $c_{v}$ at height $h$ above the distributor can be calculated from the bubble volume fraction $\varepsilon_{b}$ and the solids volume concentration in the suspension phase $c_{v s}$ according to:

$$
c_{v}=\left(1-\varepsilon_{b}\right) \cdot c_{v s}
$$

The solids volume concentration of the suspension phase can be correlated to the solids volume concentration at minimum fluidization conditions $\left(u=u_{m f}\right)$ :

$$
\frac{c_{v s}}{c_{v, m f}}=1-0.14 \cdot \operatorname{Re}_{p}^{0.4} \cdot \mathrm{Ar}^{-0.13}
$$

Reynolds and Archimedes number are defined as follows:

$$
\begin{gathered}
\operatorname{Re}_{p}=\frac{\left(u-u_{m f}\right) \cdot d_{p, s}}{v} \\
\operatorname{Ar}=\frac{d_{p, s}^{3} \cdot g}{v^{2}} \frac{\left(\rho_{s}-\rho_{f}\right)}{\rho_{f}}
\end{gathered}
$$

The bubble volume fraction is calculated from the visible bubble flow rate $\dot{V}_{b}$ and the average rise velocity of the bubbles $u_{b}$ :

$$
\varepsilon_{b}=\frac{\dot{V}_{b}}{u_{b}}
$$

The visible bubble flow rate is related to the excess gas velocity and the correlation factor $\varphi$ :

$$
\begin{gathered}
\dot{V}_{b}=\varphi\left(u-u_{m f}\right) \\
\varphi=1.45 \mathrm{Ar}^{-0.18} 10^{2}<\mathrm{Ar}<10^{4}
\end{gathered}
$$

Outside these boundaries $\varphi$ is taken as 0.8 . The bubble rise velocity is then calculated from the visible bubble flow and the bubble size $d_{b}$ at height $z$ :

$$
u_{b}=\dot{V}_{b}+0.71 \cdot \vartheta \cdot \sqrt{g \cdot d_{b}}
$$


$\vartheta$ describes the influence of the bed diameter $d_{t}$. For Geldart B powder:

$$
\vartheta=\left\{\begin{array}{cc}
1.01 & d_{t}<0.1 \mathrm{~m} \\
3.2 \sqrt{d_{t}} & 0.1 \mathrm{~m} \leq d_{t} \leq 1.0 \mathrm{~m} \\
3.2 & d_{t}>1.0 \mathrm{~m}
\end{array}\right.
$$

and for Geldart A powder respectively:

$$
\vartheta=\left\{\begin{array}{cc}
1.18 & d_{t}<0.05 \mathrm{~m} \\
3.2 \sqrt[3]{d_{t}} & 0.05 \mathrm{~m} \leq d_{t} \leq 1.0 \mathrm{~m} \\
3.2 & d_{t}>1.0 \mathrm{~m}
\end{array}\right.
$$

The initial bubble size of a technical gas distributor can be calculated according to Davidson and Schüler [7]:

$$
d_{b 0}=1.3\left(\frac{\dot{V}_{0}^{2}}{g}\right)^{0.2}
$$

$\dot{V}_{0}$ is the gas flow rate through a single nozzle e.g. a single bubble cap. For a porous plate the initial bubble size can be determined from Equation (12):

$$
d_{b 0}=\frac{2.78}{g}\left(u_{0}-u_{m f}\right)^{2}
$$

Bubble growth and splitting is calculated according to:

$$
\frac{d d_{b}}{d z}=\left(\frac{2 \cdot \varepsilon_{b}}{9 \cdot \pi}\right)^{\frac{1}{3}}-\frac{d_{b}}{3 \cdot \lambda \cdot u_{b}}
$$

The mean life time of a bubble $\lambda$ is calculated from:

$$
\lambda=280 \frac{u_{m f}}{g}
$$

If measurements of minimum fluidization velocity are available $u_{m f}$ is directly provided as input parameter otherwise it is calculated with the approximation from Wen and $\mathrm{Yu}[8]$.

\subsubsection{Description of the Upper Dilute Zone}

In the upper dilute zone above the dense bottom zone the solids are assumed to be suspended in the gas flow without the presence of a distinct bubble phase. Between the upper boundary of the bottom zone and the top of the reactor an exponential decay of the solids volume concentration is assumed [9]:

$$
c_{v, i}(h)=c_{v \infty, i}+\left(c_{v, i}\left(h_{b e d}\right)-c_{v \infty, i}\right) \cdot e^{-a\left(h-h_{b e d}\right)}
$$

An important parameter is the decay constant $a$. The solids volume concentration above transport disengaging height $c_{v \infty}$ is derived from a correlation for the elutriation constant $K_{i \infty}^{*}$ with the assumption that particles will move with a slip velocity equal to the difference of the superficial gas velocity and the terminal velocity $u_{t, i}$ of the respective particle size class $i$ :

$$
c_{v \infty, i}=\frac{G_{s \infty, i}}{\rho_{s}\left(u-u_{t, i}\right)}
$$

This assumption excludes elutriation of particles with a settling velocity higher than the superficial gas velocity. The solids flux in the reactor above transport disengaging height $G_{s \infty, i}$ is weighted with the mass fraction of particles in size class $i \Delta Q_{3, i}$ present in the reactor:

$$
G_{s \infty, i}=K_{i \infty}^{*} \cdot \Delta Q_{3, i}
$$

There are numerous correlations for the elutriation constant $K_{i \infty}^{*}$ [9], which were measured for different particle sizes, gas velocities and in fluidization columns of different size. For the present investigations the correlation from Colakyan and Levenspiel [10] was chosen:

$$
K_{i \infty}^{*}=0.011 \cdot \rho_{s} \cdot\left(1-\frac{u_{t, i}}{u}\right)^{2}
$$

In case a Circulating Fluidized Bed (CFB) is to be described, the models stated above are extrapolated to the present gas velocities. This approach has already been employed in previous investigations (e.g. [11]).

\subsection{Reactions}

First the solids conversion is defined as:

$$
X_{s}=\frac{\dot{m}_{r e d}}{\dot{m}_{o x}+\dot{m}_{r e d}}
$$

Reactions are assumed to take place in the suspension phase of the bottom zone and the freeboard where reactant gas and Oxygen Carrier particles contact each other. The heterogeneous reactions are calculated according to a shrinking core model [9]. The solids conversion rate is defined in dependency of the time necessary for full conversion $\tau$ :

$$
\frac{d \overline{X_{s}}}{d t}=\frac{3 \cdot\left(1-\overline{X_{s}}\right)^{\frac{2}{3}}}{\tau}
$$

The time limiting step is assumed to be the reaction and not any diffusion phenomenon. Then $\tau$ is defined as:

$$
\tau=\frac{\rho_{m} \cdot d_{g}}{2 \cdot b \cdot k \cdot C^{n}}
$$

with $\rho_{m}$ the molar density of the solid reactant, $d_{g}$ the diameter of the spherical grains of pure reactant on the particles, the stoichiometric factor $b$, the chemical reaction rate constant $k$ and the local reactant concentration $C$ to the power of $n$, the reaction order.

The temperature dependency of the chemical reaction rate constant $k$ follows the Arrhenius law:

$$
k=k_{0} \cdot e^{\frac{-E_{a}}{R \cdot T}}
$$


The solids reaction rate $r_{s}$ is then derived from:

$$
r_{s}=-c_{v} \cdot \rho_{m} \cdot \frac{d \overline{X_{s}}}{d t}
$$

Gas reaction rate $r_{g}$ is derived by dividing with the stoichiometric factor $b$ :

$$
r_{g}=\frac{r_{s}}{b}
$$

In dependency of the gaseous reactant, the reactions inside the reactors lead to changes in the volume flow. Since the model assumes excess gas to rise in the bubble phase while the suspension stays fluidized at $u_{m f}$ the description of the concentration change in the bottom zone has to account for both diffusive and convective mass transfer between the bubble and the suspension phase. The diffusive flow is described according to Sit and Grace [12]:

$$
k_{g}=\frac{u_{m f}}{3}+\sqrt{\frac{4 \cdot D_{g} \cdot \varepsilon_{m f} \cdot u_{b}}{\pi \cdot d_{b}}}
$$

$D_{g}$ denotes the molar binary diffusion coefficient. The transfer area $a_{\text {transfer }}$ is defined as:

$$
a_{\text {transfer }}=6 \frac{\varepsilon_{b}}{d_{b}}
$$

The convective transport of gas between the suspension and bubble phase and the dilution of reactant gases by product gases is accounted for according to Sitzmann et al. [13]:

$$
K_{Q}=-u_{m f} \frac{1}{P} \frac{d P}{d z}-\left(1-\varepsilon_{b}\right) r_{g} \frac{R \cdot T}{P} \sum_{i} v_{i}
$$

Neglecting the influences of particle acceleration, the pressure profile can be derived from:

$$
\frac{d P}{d z}=-\rho_{s} \cdot c_{v} \cdot g
$$

As mentioned in Section 1.1 and shown in Figure 1, the concentration of the reactant is tracked along the height of the reactor. In the bottom zone it is further distinguished between for the bubble and the suspension phase with individual reactant gas concentrations. The respective differential equations describing the change of reactant concentration with reactor height can be set up as:

$$
\begin{gathered}
\frac{d C_{s}}{d z}=\frac{\left(1-\varepsilon_{b}\right) \cdot r_{g}+k_{g} \cdot a_{\text {transfer }} \cdot\left(C_{b}-C_{s}\right)-K_{Q} \cdot C_{s}}{\left(1-\varepsilon_{b}\right) \cdot u_{m f}} \\
\frac{d C_{b}}{d z}=\frac{-k_{g} \cdot a_{\text {transfer }} \cdot\left(C_{b}-C_{s}\right)+K_{Q} \cdot C_{s}-C_{b} \frac{d u}{d h}}{u-\left(1-\varepsilon_{b}\right) \cdot u_{m f}}
\end{gathered}
$$

In the freeboard region the following relation is used:

$$
\frac{d C}{d z}=\frac{r_{g}}{u}
$$

\subsection{Population Balance Modeling}

The focus of this investigation is to simulate the flows as well as the particle size distributions inside this system of interconnected fluidized bed reactors. This is done by a population balance approach which has been adapted from Werther \& Hartge [14]. The original model was a description for the unsteady case. For steady-state calculations a modified approach is shown here. In this model it is assumed that particles do not break and the dominating attrition mechanism is abrasion, which is a reasonable assumption for catalyst attrition under normal (circulating) fluidized bed reactor operating conditions [15]. Exceeding the range of normal operating conditions could lead to increasing fragmentation. The range of operating conditions in which fragmentation can be neglected is solids specific and cannot be generalized. The produced fines are assumed to be small in size and will be added to the first particle size interval. Due to this abrasion the mother particles will shrink in size and a certain amount of particles within the interval i will become smaller than the lower bound of the size interval. This amount is transferred into the next smaller interval $i-1$. For any size interval except the first and last, this leads to::

$$
d \dot{m}_{i}=-\dot{m}_{a t t, i}-\dot{m}_{i, i-1}-\dot{m}_{i+1, i} \quad 1<i<n
$$

The first interval collects all the produced fines:

$$
\dot{m}_{1}=\sum_{i=2}^{n} \dot{m}_{a t t, i}+\dot{m}_{2,1}
$$

while the last interval does not gain any material:

$$
\dot{m}_{n}=-\dot{m}_{a t t, n}-\dot{m}_{n, n-1}
$$

The mass that is transferred to the next smaller interval due to particle shrinkage can be calculated according to Equation (35). A detailed derivation of this equation will be published soon [16]:

$$
\dot{m}_{i, i-1}=\frac{1}{6} \frac{\dot{m}_{a t t, i}}{\left(d_{p, i}-d_{p, i-1}\right)} \frac{d_{p, i-1}^{3}}{\bar{d}_{p, i}^{2}}
$$

In a system of coupled fluidized bed reactors three major sources of attrition can be distinguished [17]. First, attrition can be caused by the solids movement induced by the bubbles in a fluidized bed. Secondly, there is attrition due to gas jets issuing from the orifices and the third important attrition source is the solids recovery in the cyclones. The mass of produced fines inside a bubbling fluidized bed reactor is calculated from the equations given by Merrick and Highley [18] and Reppenhagen and Werther [17] according to:

$$
\begin{gathered}
\dot{m}_{\text {att }, \text { bubble }, i}=k_{b} \cdot m_{\text {bed }} \cdot \Delta Q_{3, i} \cdot\left(u_{0}-u_{m f}\right) \\
\dot{m}_{\text {att }, j e, i}=n_{0} \cdot k_{j} \cdot d_{p, i} \cdot \rho_{s} \cdot d_{o r}^{2} \cdot u_{o r}^{3} \cdot \Delta Q_{3, i}
\end{gathered}
$$

The model for bubble induced attrition is also employed for the description of Circulating Fluidized Beds. This is an extrapolation of the model to the present gas velocities. 
The attrition occurring in the cyclone is calculated according to Reppenhagen and Werther [17]:

$$
\dot{m}_{\text {att }, \text { cyclone }, i}=k_{c} \cdot \dot{m}_{i n} \cdot \Delta Q_{3, i} \cdot d_{p, i} \frac{u_{i n}^{2}}{\sqrt{\mu}}
$$

For the attrition calculation one material specific constant for each attrition mechanism is needed $\left(k_{b}, k_{j}, k_{c}\right)$. These constants have to be calculated from experimental results. Additionally bubble induced attrition depends on the bed mass $m_{b e d}$, as well as the excess gas velocity and the fraction of particles in size interval $i \Delta Q_{3, i}$. The grid jet attrition is also influenced by the diameter of the orifices $d_{o r}$ as well as the velocity of gas issuing from the orifices $u_{o r}$ and the number of orifices $n_{0}$. The cyclone attrition depends on the mass flow of solids entering the cyclone $\dot{m}_{i n}$, the mass fraction of particles in size interval $i$, the size of particles in class $i d_{p, i}$, the gas velocity at the inlet of the cyclone and the solids load at the cyclone inlet $\mu$. The solids load of the gas flow is defined as:

$$
\mu=\frac{\dot{m}_{i n}}{A_{t} \cdot u \cdot \rho_{g}}
$$

A general verification of the aforementioned procedure for the prediction of attrition in fluidized bed processes with data from industrial plants is often difficult because operational parameters and detailed process design are usually considered proprietary. However, just recently this procedure has been applied to DuPont's process for maleic anhydride production [19]. A comparison of the predicted values with measured values of catalyst loss in the industrial process showed a general agreement. Predicted and measured catalyst losses are of the same order of magnitude and the model could correctly predict the influences of operational parameters on catalyst losses. This approach has also been applied to CFB power plants and the results were verified against measurements with reasonable agreement [20].

\subsection{Simulation}

For the investigation of the CLC process, the flowsheet simulation environment SolidSim [21] has been selected. SolidSim is a commercial software package for the simulation of solids processes and was originally developed at the Institute of Solids Process Engineering and Particle Technology of the Hamburg University of Technology [22]. SolidSim employs a sequential modular approach for the simulation of the steadystate behavior of solids processes. Unit operations are calculated in series and loops are solved by fixed-point iteration of the unit operations. Cyclones are calculated with the built in unit model whereas the fluidized bed reactors were developed by the authors of this publication.

\section{RESULTS AND DISCUSSION}

\subsection{Definition of the Test Case}

\subsubsection{Oxygen Carrier}

For the simulations the copper based OC Cu10Al-I was selected which was produced and thoroughly investigated by the CSIC [23, 24]. According to those references this carrier has a total $\mathrm{CuO}$ content of $13 \mathrm{wt} \%$ and an active $\mathrm{CuO}$ content of $10 \mathrm{wt} \%$. The support material is a porous aluminum oxide (Aldrich Chemical Co.). The apparent density is given as $1800 \mathrm{~kg} / \mathrm{m}^{3}$. The parameters necessary for reaction calculations for this carrier are shown in Table 1. The kinetic parameters have been derived from thermogravimetric analysis and evaluated with the shrinking core model.

TABLE 1

Reaction characteristics of Cu10Al-I Oxygen Carrier with methane and oxygen

\begin{tabular}{c|c|c|c}
\hline Parameter & Unit & $\mathrm{CH}_{4}$ & $\mathrm{O}_{2}$ \\
\hline$\rho_{m}$ & $\mathrm{~mol} / \mathrm{m}^{3}$ & 80402 & 140251 \\
$d_{g}$ & $\mathrm{~m}$ & $2.0 \times 10^{-10}$ & $1.15 \times 10^{-10}$ \\
$k_{0}$ & $\mathrm{~mol}^{1-n} \mathrm{~m}^{3 \mathrm{n}-2} \mathrm{~s}^{-1}$ & $4.5 \times 10^{-4}$ & $4.7 \times 10^{-6}$ \\
$E_{a}$ & $\mathrm{~J} / \mathrm{mol}^{n}$ & 60000 & 15000 \\
$n$ & - & 0.4 & 1 \\
\hline
\end{tabular}

The particle size distribution of the Oxygen Carrier feed stream that compensates the OC loss in the simulations was adopted from a long-term chemical looping experiment at Chalmers University with a different OC [25] and is shown in Figure 2.

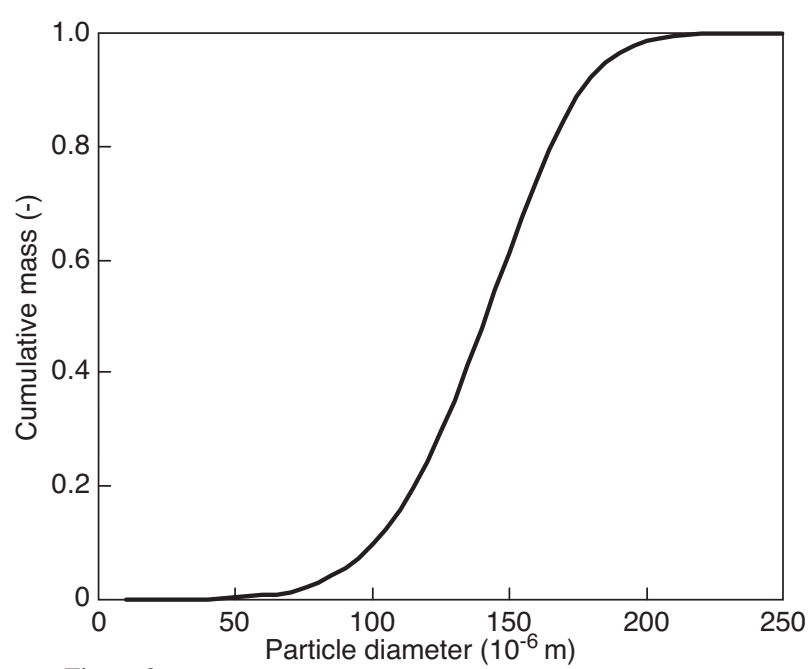

Figure 2

Particle size distribution of the OC feed stream for compensation of the OC loss of the process. 
For the calculation of the attrition the material specific constants in Equations (36-38) have to be known. These however are not available for the chosen Oxygen Carrier hence the material specific values from a Vanadium Phosphorous Oxide (VPO) catalyst have been taken. This catalyst has undergone extensive testing and was also industrially used in a process of coupled fluidized bed reactors to produce maleic anhydride from C4 feedstock [26]. For comparison averaged values of FCC-catalysts have also been used in the simulations. FCC catalysts are used in the fluid catalytic cracking of crude oil into higher value products of lower molecular weight hydrocarbons and have already undergone a long period of optimization with respect to their attrition behavior. Oxygen Carriers still have to undergo this process of optimization and therefore it can be assumed that they will show higher attrition rates. The FCC attrition rates therefore stand for an optimal Oxygen Carrier. An overview on experimentally determined attrition constants is found in [27]. The values of the material specific constants for both cases are shown in Table 2.

TABLE 2

Material specific attrition constants for FCC and VPO catalysts

\begin{tabular}{c|c|c|c}
\hline & Unit & FCC & VPO \\
\hline$k_{b}$ & $1 / \mathrm{m}$ & $1.0 \times 10^{-8}$ & $3.5 \times 10^{-8}$ \\
$k_{j}$ & $\mathrm{~s}^{2} / \mathrm{m}^{3}$ & $3.5 \times 10^{-5}$ & $2.2 \times 10^{-5}$ \\
$k_{c}$ & $\mathrm{~s}^{2} / \mathrm{m}^{3}$ & $1.0 \times 10^{-3}$ & $4.5 \times 10^{-3}$ \\
\hline
\end{tabular}

\subsubsection{Reactions}

The selected Oxygen Carrier is composed of aluminum oxide and copper oxide. Methane was chosen as fuel and air was chosen as oxidizing agent. The respective reaction equations are shown below.

Oxidation:

$$
\begin{gathered}
\mathrm{O}_{2}+2 \mathrm{Cu} \rightarrow 2 \mathrm{CuO} \\
\Delta H_{R}^{o}=-312.1 \frac{\mathrm{kJ}}{\mathrm{mol}}
\end{gathered}
$$

Reduction:

$$
\begin{gathered}
\mathrm{CH}_{4}+4 \mathrm{CuO} \rightarrow 4 \mathrm{Cu}+\mathrm{CO}_{2}+2 \mathrm{H}_{2} \mathrm{O} \\
\Delta H_{R}^{o}=-178.0 \frac{\mathrm{kJ}}{\mathrm{mol}}
\end{gathered}
$$

According to the above equations the stoichiometric factor $b$ for the reaction calculations is 2 for the oxidation and 4 for the reduction reaction of the OC.

\subsubsection{Process Setup}

Chemical Looping Combustion was studied in different types of unit configurations $[1,28,29]$ but systems of interconnected fluidized beds dominate the literature due to the

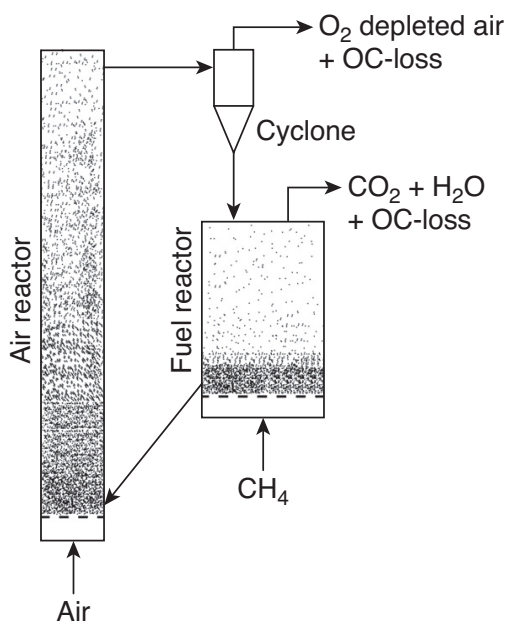

Figure 3

Base case setup based on Lyngfelt et al. [1].

implied good gas/solids contact. In 2001 Lyngfelt et al. [1] made a first sketch of a process similar to the one shown in Figure 3. The air reactor is realized as a Circulating Fluidized Bed (CFB) whereas the fuel reactor is a Bubbling Fluidized Bed (BFB). The setup sketched in Figure 3 is chosen as the reference setup of the simulations.

The setup was simulated in pilot scale $\left(50 \mathrm{~kW}_{\mathrm{th}}\right)$ and in $100 \mathrm{MW}_{\text {th }}$ scale to see effects of scale-up. Porous plates were chosen as gas distributors for the pilot scale setup. For the large scale this would not reflect a realistic design and therefore bubble caps were chosen. Bubble caps have the potential to reduce gas jets issuing into the bed of particles. Usually the gas leaves the caps at velocities in the range of $10-15 \mathrm{~m} / \mathrm{s}$ compared to $50-100 \mathrm{~m} / \mathrm{s}$ in the orifices of gas distributors [30]. Thus Oxygen Carrier particles will be exposed to less stress and attrition is reduced.

\subsection{Sizing of the Plants}

The diameters of the reactors were determined according to predefined boundary conditions. For both scales a global air to fuel ratio of 1.2 was chosen. Together with the known fuel power and fixed gas velocity the diameters can be calculated. Starting the design with the air reactor it has to be considered that if the fuel is completely converted the oxygen demand will be at its maximum and the maximum amount of oxygen will be consumed in the air reactor. Accordingly the volume flow in the air reactor decreases due to reaction to its largest extent. For this case the superficial gas velocity at the top of the air reactor should be $7 \mathrm{~m} / \mathrm{s}$. This leads to air reactor diameters of $0.1 \mathrm{~m}$ for the pilot plant and $4.63 \mathrm{~m}$ for the large plant. For the fuel reactor it was strived for superficial gas velocities in the range of $0.25 \mathrm{~m} / \mathrm{s}$ to $0.5 \mathrm{~m} / \mathrm{s}$. With $0.375 \mathrm{~m} / \mathrm{s}$ 
being the middle of this range, this gas velocity was initially aimed for at the top of the reactor at full methane conversion. Full conversion is accompanied by an increase in volume flow by the factor of 3 . At the gas inlet of the reactor the superficial gas velocity will be $0.125 \mathrm{~m} / \mathrm{s}$ which still is roughly 3 times $u_{m f}$ for the chosen OC. The diameter of the pilot scale fuel reactor is then $0.23 \mathrm{~m}$ and $10.6 \mathrm{~m}$ is the diameter of the large scale fuel reactor, respectively. After choosing the diameters of the reactors, the bubble cap gas distributors can be designed. Having 8 orifices per cap and designing for a pressure drop of approximately $2500 \mathrm{~Pa}, 400 \mathrm{caps} / \mathrm{m}^{2}$ in the air reactor and $64 \mathrm{caps} / \mathrm{m}^{2}$ in the fuel reactor will be appropriate. The height of the air reactor for the pilot scale was initially set to $10 \mathrm{~m}$ in order for the plant to still fit into a regular pilot plant building. In CLC a high circulation flow of OC between the reactors is necessary to provide sufficient oxygen transport capacity. In this study it was aimed for a solids flux in the air reactor $\left(G_{s}\right)$ of $45 \mathrm{~kg} / \mathrm{m}^{2} \mathrm{~s}$. The correlation (18) for the elutriation constant predicts significantly lower $G_{s}$ values of less than $50 \%$ of the desired flux above TDH. To achieve a high solids flux in spite of the low values predicted for heights above TDH the reactor height is limited thus the gas exit is located below TDH. The height necessary to achieve the targeted solids flux is dependent on the decay constant $a$. This parameter determines the rate of decay of the solids volume concentration and thereby also the solids distribution in reactor and ultimately the conversion in the reactor. Even though there have been numerous investigations towards this parameter it is rather difficult to choose the correct value from literature data. Literature data on this parameter seems scattered and sketchy [9]. Future work of the authors will be directed to this issue. For this work the product $a \cdot u_{0}$ was chosen to be 3 according to the data given by Kunii and Levenspiel [9]. The actual value for $a$ depends on the conversion and is for a gas velocity of $7 \mathrm{~m} / \mathrm{s} 0.43$. Finally the necessary solids inventory of the reactor can be determined to a mass of $2.24 \mathrm{~kg}$ that applies a pressure drop of $5300 \mathrm{~Pa}$. To maintain comparability between the two scales the large scale air reactor was designed to achieve a similar solids flux per unit square area. This led to a height of $10.5 \mathrm{~m}$ at a pressure drop of $8000 \mathrm{~Pa}$ or a solids inventory of $13700 \mathrm{~kg}$. The different pressure drops are due to the different wall interactions. In the small scale process calculations will quickly lead to bubble sizes equal to the diameter of the air reactor and thus the diameter will limit the bubble size quickly. This is different for the large scale air reactor and accordingly the bottom zone is denser and lower compared to the small scale air reactor (max. $c_{v}$ of 0.159 compared to 0.065). In the fuel reactor, the height is chosen to be above TDH in order to minimize elutriation. The solids volume concentration in the freeboard decreases faster compared to the air reactor. The product was chosen to be 12 in the fuel reactor. In the fuel reactor this value has hardly an impact on the performance since the reactions in the freeboard of the fuel reactor are negligible compared to the reactions in the bottom zone. The height of the small scale fuel reactor was chosen to be $2 \mathrm{~m}$ while the height of the large scale reactor was chosen to be $6 \mathrm{~m}$. The inventory in the small scale fuel reactor is $11.5 \mathrm{~kg}$, corresponding to a pressure drop of 2750 $\mathrm{Pa}$. Initially a comparable pressure drop was also chosen for the large scale process. Due to the different gas distributor a larger bypass flow of fuel gases through the larger bubbles was detected during initial isolated fuel reactor simulations. If the fuel reactor is fed with fully oxidized OC only $82.7 \%$ of the fuel is converted and $42.9 \%$ of the solids. A larger bypass flow through the bubbles in the large scale is to be expected, since bubble sizes at the gas distributor differ significantly. The initial bubble size calculated is $0.0689 \mathrm{~m}$ for the large scale compared to $0.0039 \mathrm{~m}$ for the small scale fuel reactor. To increase the gas conversion in the large scale fuel reactor a higher bed height was chosen (new inventory: 140 $000 \mathrm{~kg} / 10000 \mathrm{~Pa}$ pressure drop) and at the same time the reactor diameter was increased to $13 \mathrm{~m}$ to decrease the superficial gas velocity to $0.25 \mathrm{~m} / \mathrm{s}$ for all following simulations. This led to a fuel conversion of $96.0 \%$ and an initial bubble size of $0.0585 \mathrm{~m}$. In total the large scale process has a solids inventory of $153700 \mathrm{~kg}$ and the small scale process an inventory of $13.74 \mathrm{~kg}$.

After the reactors have been dimensioned, the cyclone after the air reactor is to be designed. The boundary condition in this case was not to exceed $20 \mathrm{~m} / \mathrm{s}$ gas velocity at the inlet of the cyclone in order to avoid fragmentation of Oxygen Carrier particles. The cyclone was designed with the help of the design modus of the supplied cyclone model of SolidSim. The user can enter a desired pressure drop and SolidSim optimizes the size of the cyclone according to the selected geometrical concepts until a geometry is found that fulfills the pressure drop criterion and has the highest possible separation efficiency. Separation efficiency is calculated according to the Muschelknautz et al. model [31]. This procedure led to the cyclone geometries listed in Table 3 and a pressure drop of $1200 \mathrm{~Pa}$.

TABLE 3

Determined geometry of the air reactor cyclone in both scales

\begin{tabular}{l|c|c}
\hline Parameter & $50 \mathrm{~kW}_{\text {th }}$ scale & $100 \mathrm{MW}_{\text {th }}$ scale \\
\hline Inlet height & $0.051 \mathrm{~m}$ & $2.480 \mathrm{~m}$ \\
Inlet width & $0.053 \mathrm{~m}$ & $2.540 \mathrm{~m}$ \\
Main diameter & $0.070 \mathrm{~m}$ & $3.380 \mathrm{~m}$ \\
Total height & $0.263 \mathrm{~m}$ & $12.700 \mathrm{~m}$ \\
Vortex-finder diameter & $0.035 \mathrm{~m}$ & $1.690 \mathrm{~m}$ \\
Depth of immersion & $0.053 \mathrm{~m}$ & $2.540 \mathrm{~m}$ \\
Cylindric height & $0.211 \mathrm{~m}$ & $10.160 \mathrm{~m}$ \\
Apex nozzle diameter & $0.035 \mathrm{~m}$ & $1.690 \mathrm{~m}$ \\
\hline
\end{tabular}


Finally a summary of all input parameters is shown in Table 4.

TABLE 4

Simulation input parameters

\begin{tabular}{l|c|c|c}
\hline Parameter & Unit & $50 \mathrm{~kW}_{\text {th }}$ scale & $100 \mathrm{MW}_{\text {th }}$ scale \\
\hline Height air reactor & $\mathrm{m}$ & 10.00 & 10.50 \\
Height fuel reactor & $\mathrm{m}$ & 2.00 & 6.00 \\
Diameter air reactor & $\mathrm{m}$ & 0.10 & 4.63 \\
Diameter fuel reactor & $\mathrm{m}$ & 0.23 & 13.00 \\
Pressure at reactor bottom & $\mathrm{Pa}$ & 101325 & 101325 \\
Temperature air reactor & $\mathrm{K}$ & 1173 & 1173 \\
Temperature fuel reactor & $\mathrm{K}$ & 1123 & 1123 \\
Global air to fuel ratio & - & 1.2 & 1.2 \\
Air feed & $\mathrm{kg} / \mathrm{s}$ & 0.01945 & 43.080 \\
$\mathrm{CH}_{4}$ feed & $\mathrm{kg} / \mathrm{s}$ & 0.00090 & 1.993 \\
$\Delta p$ air reactor & $\mathrm{Pa}$ & 5300 & 8000 \\
$\Delta p$ fuel reactor & $\mathrm{Pa}$ & 2750 & 10000 \\
$\varepsilon_{m f}$ & - & 0.45 & 0.45 \\
Decay constant $a \cdot \mathrm{u}_{0}$ & $1 / \mathrm{s}$ & 3 & 3 \\
\hline
\end{tabular}

\subsection{Simulation Results without Attrition}

As noted in Section 2.2, the aim during sizing was to obtain solids fluxes of approximately $45 \mathrm{~kg} / \mathrm{m}^{2} \mathrm{~s}$ based on the air reactor diameter. This value is slightly changing during the simulations since it is dependent on the present particle size distribution. For the small scale process the steady-state value is $43.6 \mathrm{~kg} / \mathrm{m}^{2} \mathrm{~s}$ for simulations without attrition. The $100 \mathrm{MW}_{\text {th }}$ scale simulations reached $44.8 \mathrm{~kg} / \mathrm{m}^{2} \mathrm{~s}$ at steady-state for a similar simulation. These values correspond to absolute values of the circulation mass flow of $0.339 \mathrm{~kg} / \mathrm{s}$ for the small scale and $746.3 \mathrm{~kg} / \mathrm{s}$ for the large scale, respectively. The area specific solids fluxes lie within the range of applied CFB technology. CFB combustors are usually expected to operate at roughly $15 \mathrm{~kg} / \mathrm{m}^{2} \mathrm{~s}$ [32]. Higher values, exceeding $100 \mathrm{~kg} / \mathrm{m}^{2} \mathrm{~s}$ are known from the operation of FCC processes which involve fine catalysts [32]. The particle sizes in this study lie in between those of CFB combustors and FCC units. Nevertheless, to reach such values during the simulations the air reactor had to be limited in height. This might lead to incomplete conversion of the $\mathrm{OC}$ in the air reactor and in fact this could be observed in the simulations. The solids are almost completely converted in the fuel reactor $\left(X_{s}=99.8 \%\right.$ in large scale / $X_{s}=94.7 \%$ in small scale) while after the air reactor $52.3 \%$ (large scale) of the solids are still in reduced state ( $44.2 \%$ for the small scale). This corresponds to air conversions of $72.4 \%$ for the large scale and $77.5 \%$ for the small scale. Especially the large scale process performance suffers from insufficient oxygen transport due to limited solids conversion in the air reactor. This incomplete conversion is due to the limited height. The reaction is not fast enough to fully convert the OC particles within this height. Increasing the $k_{0}$ for the oxidation by a factor of 10 leads to an increased fuel gas conversion of $96.0 \%$ in the large scale and the solids are only reduced to $53.1 \%$ at the exit of the fuel reactor. After the air reactor solids are oxidized to $96.9 \%$. So even if oxidation is almost complete after the air reactor a full conversion of fuel gas is not possible in this large scale fuel reactor. A significant amount of reactant gas is bypassing the fluidized bed through the bubble phase because rather large bubbles are forming. In the small scale process the bubbles are smaller due to the porous plate gas distributor. If sufficient oxygen is transported to the fuel reactor with the OC flow, the fuel gas conversion will reach $99.7 \%$.This is a well known scale-up issue that has together with possible measures been discussed by Werther [33, 34] for instance. For example heat exchange tube bundles or baffles will interrupt the bubble growth and a different gas distributor could also lower the initial bubble size.

\subsection{The Role of Attrition}

Attrition will lead to fine particle generation while the mother particles will shrink slightly in size. Retaining the produced small particles in the system is difficult and hence the mass loss of OC particles will depend on the attrition behavior of the respective particles. To investigate the influence of attrition on the process performance simulations have both been carried out with and without attrition regarded. In Figure 4 the losses of OC particles are shown per MWh of

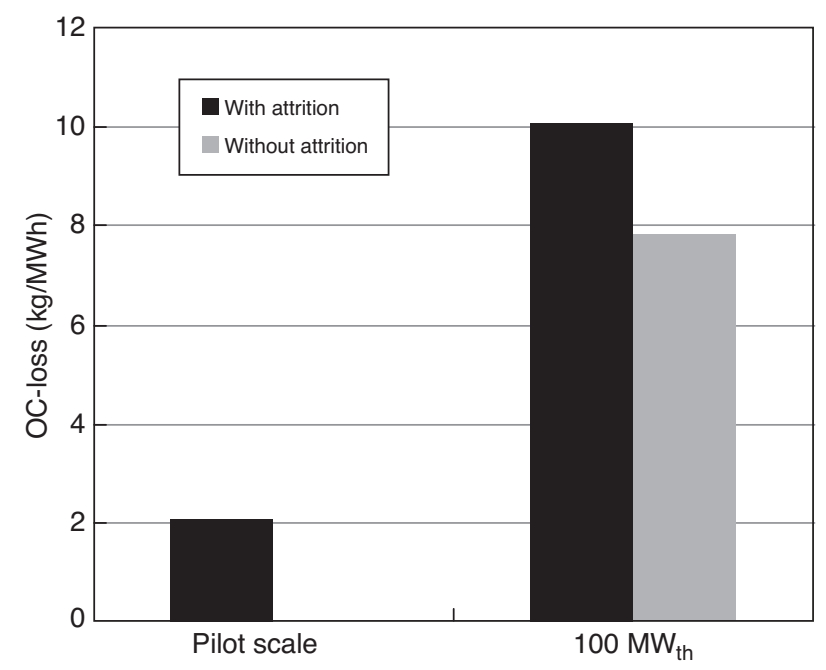

Figure 4

Oxygen Carrier loss in kg per MWh of thermal energy released with and without consideration of particle attrition for both scales. 
thermal energy released. The simulation results with attrition regarded have been achieved by the use of the VPO attrition constants stated in Section 2.1.1. It can be observed that in the small scale there is no eminent loss of OC particles when attrition is not regarded. This means at steady-state particles are circulating between the reactors that can be separated to almost $100 \%$ in the cyclone after the air reactor. This is not the case in the large scale process. Even without attrition regarded a significant amount of OC is lost due to inefficient solids separation in the cyclone. This is a consequence of the Muschelknautz et al. cyclone separation model [31]. The capture efficiency drops from virtually $100 \%$ to $99.972 \%$ during the scale up. Attrition itself accounts for a loss of $2.05 \mathrm{~kg} / \mathrm{MWh}$ in the small scale and $2.25 \mathrm{~kg} / \mathrm{MWh}$ in the large scale.

Another interesting question arising is where the losses mainly originate from. There are two possible locations where OC can be lost. First OC can be lost in the overflow of the cyclone after the air reactor and secondly particles can be elutriated from the fuel reactor. Figure 5 shows that in the small scale process the majority of the loss $(99.6 \%$ with attrition regarded) originate from elutriation from the fuel reactor whereas in the large scale losses mainly originate from the air reactor cyclone $(82.2 \%$ with attrition regarded). Comparing only the losses from the fuel reactor due to elutriation for both scales it has to be noticed that those values are not exactly the same. A part of the particles that would be elutriated in the fuel reactor will already leave the cycle through the air reactor cyclone in the large scale process and accordingly the loss due to entrainment in the large scale fuel reactor is slightly lower compared to the small scale fuel reactor.
To investigate how a different attrition behavior influences Oxygen Carrier losses simulations have been carried out with FCC catalyst like attrition behavior of the OC. The simulations show for the large scale process that the total OC loss is lowered from $10.07 \mathrm{~kg} / \mathrm{MWh}$ to $8.31 \mathrm{~kg} / \mathrm{MWh}$ which a significant drop compared to $7.82 \mathrm{~kg} / \mathrm{MWh}$ of loss for the simulations without attrition. Most of the attrition is in all simulations generated in the cyclones, the bubble induced attrition in the fluidized beds accounts for only approximately $3 \%$ of the attrition. Therefore the significantly lower cyclone attrition constant for the FCC has a large influence on the total attrition. In the small scale the OC loss is reduced from $2.06 \mathrm{~kg} / \mathrm{MWh}$ to $0.49 \mathrm{kWh}$ compared to $0.01 \mathrm{~kg} / \mathrm{kWh}$ for the case without attrition. In the small scale attrition in the fluidized beds accounts for approximately $6 \%$ of the total attrition.

\subsection{Variation of the Solids Recovery}

In section 2.4 it was pointed out that most of the OC loss in the large scale process is due to inefficient solids separation in the air reactor cyclone and thus a large amount of solids is leaving the cycle with the flow of oxygen depleted air. On the other hand most of the OC losses in the small scale originate from elutriation in the fuel reactor. The question if additional cyclones can lower the loss of OC particles has therefore to be answered. Accordingly the following different changes in process setup have been investigated:

- introduction of a second-stage air reactor cyclone;

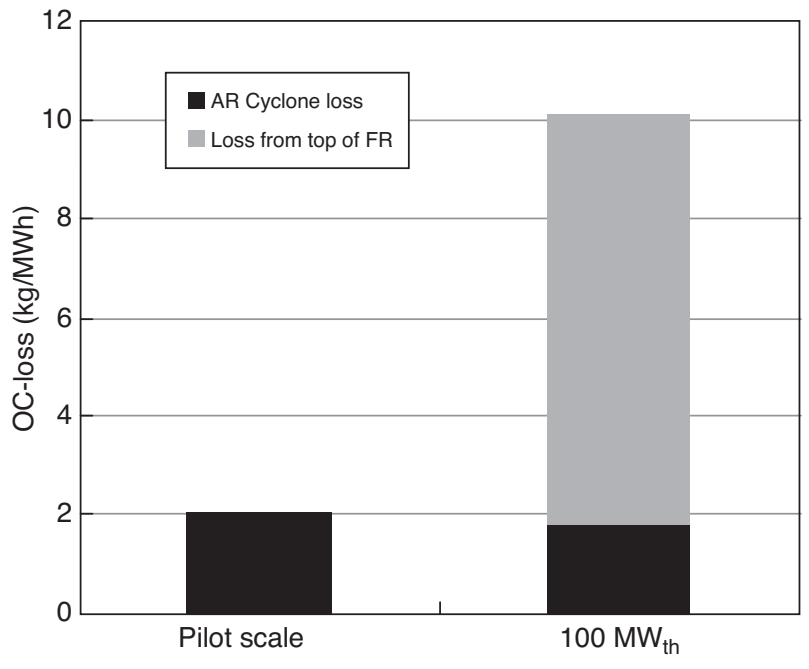

Figure 5

Origin of OC losses for the simulation with attrition in both scales.

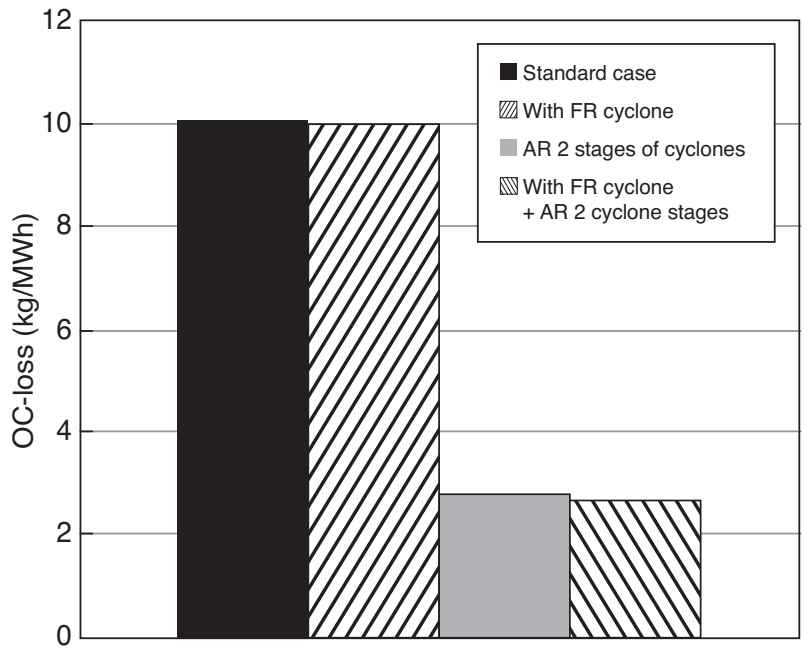

Figure 6

Influence of changes in the solids recovery on the overall OC loss per MWh of thermal energy produced for the 100 MWth process. 


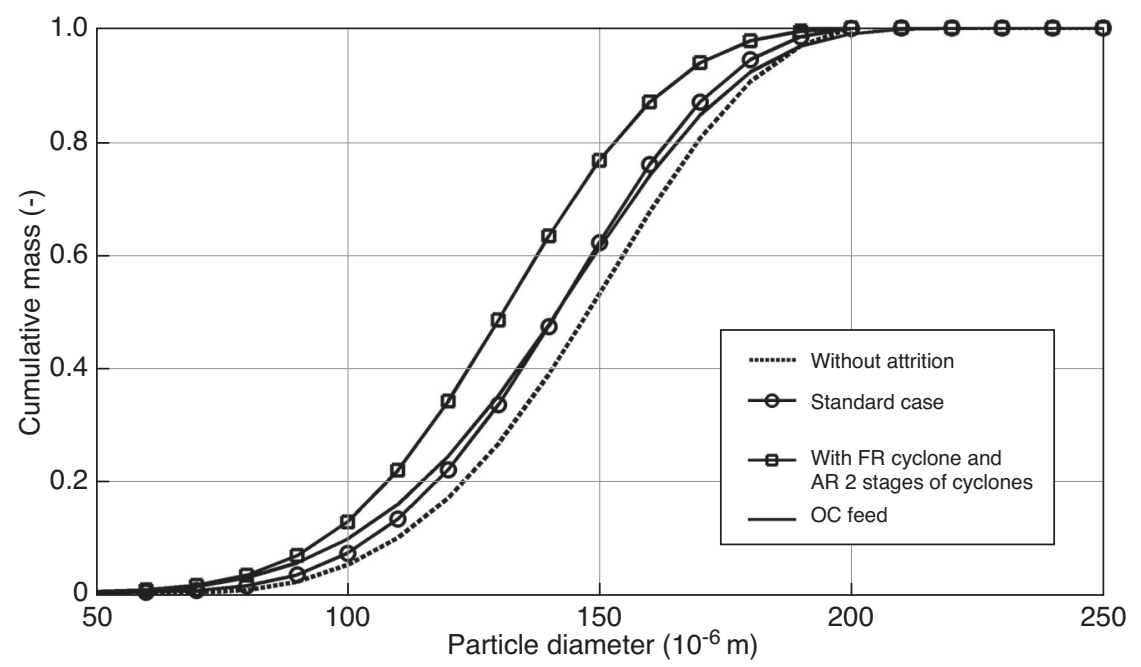

Figure 7

Particle size distributions of the OC flow circulating between the reactors for the different simulations of the $100 \mathrm{MW}_{\mathrm{th}}$ case.

- additional fuel reactor cyclone with a return leg to the fuel reactor entry;

- the combination of both changes mentioned above.

Figure 6 shows the results of those changes for the 100 $\mathrm{MW}_{\text {th }}$ scale unit. It can be observed that an additional secondary cyclone stage after the air reactor leads to a considerably reduced loss of OC particles. Contrary an additional cyclone to clean the off-gas from the fuel reactor is hardly having any influence on the OC loss. The particle size distribution of the process with fully equipped solids recovery system, in its standard setup, without recognition of attrition and the OC feed stream that compensates the OC losses are shown together in Figure 7. The Particle Size Distribution (PSD) of the simulation without attrition is shifted towards larger particles compared to the PSD of the OC compensation feed. If attrition is regarded during the calculations, the PSD is close to the PSD of the feed material. Equipping the solids separation system with additional cyclones leads to a shift of the PSD towards smaller particles. Compared to the standard setup a more sophisticated solids recovery system is able to keep smaller particles inside the loop. The fuel gas conversion is slightly influenced by the changes in the solids recovery system. The addition of a secondary air reactor cyclone stage increases the fuel gas conversion from $90.6 \%$ to $92.1 \%$. This increase is to be explained with a higher mean oxidation degree of the solids that enter the fuel reactor. On contrary the addition of a fuel reactor cyclone lowers the fuel gas conversion to $90.0 \%$. The additional flow of entrained solids in reduced state that are fed back to the fuel reactor entry lowers the mean oxidation

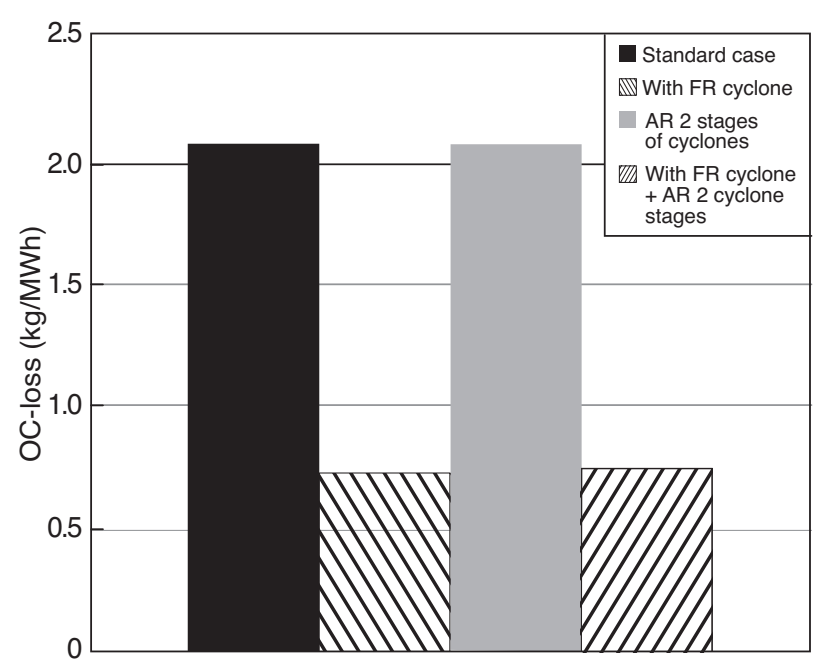

Figure 8

Influence of changes in the solids recovery on the overall $\mathrm{OC}$ loss per MWh of thermal energy produced for the $50 \mathrm{~kW}_{\text {th }}$ process.

level of the solids entering the fuel reactor. The combination of one additional cyclone after the fuel reactor and a secondary cyclone stage after the air reactor leads to the lowest conversion of $89.1 \%$. This appears to be due to slight changes in the fluid dynamics in the fuel reactor that are caused by differences in the particle size distribution.

The small scale unit shows a slightly different behavior as it can be observed in Figure 8. Since most of the losses 


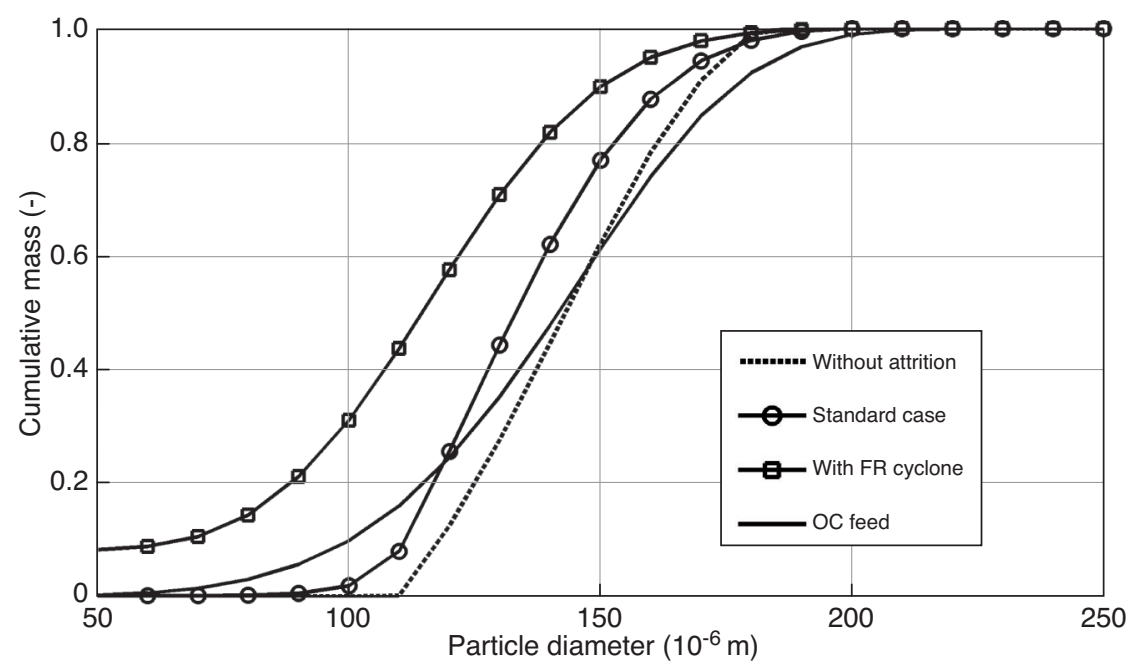

Figure 9

Particle size distributions of the OC flow circulating between the reactors for the different simulations of the $50 \mathrm{~kW}_{\mathrm{th}}$ case.

originate from fuel reactor elutriation $(99.6 \%)$ and small cyclones are more efficient than large ones, an additional fuel reactor cyclone does exhibit a noticeable influence on the OC loss of the small scale unit. In this case on the other hand an additional secondary cyclone stage after the air reactor hardly decreases the OC loss. The PSD of the circulating mass flow at steady-state is shown in Figure 9 for the simulations of the standard case, the setup with an additional fuel reactor cyclone and for the OC feed. In general the differences between the PSDs of the small and the large scale process have to be noticed. In the small scale process greater deviations from the PSD of the OC feed can be observed. The simulation without attrition is still the one with the largest particles at steady-state. The setup with improved solids recovery is again the one with the smallest particles circulating at steady-state. The higher efficiency of the solids recovery in smaller cyclones can also be seen here. A significant amount of particles $<50 \mu \mathrm{m}$ can be kept in the system.

\section{CONCLUSIONS}

In the present work a Chemical Looping Combustion process for gaseous fuels of interconnected fluidized bed reactors was simulated and investigated towards the influence of attrition and solids recovery on the process performance. The simulations are based on laboratory investigations of the attrition behavior of industrial catalysts for fluidized bed processes. The CLC process was simulated in $100 \mathrm{MW}_{\text {th }}$ scale and in
$50 \mathrm{~kW}_{\text {th }}$ scale which enabled a direct assessment of similarities and differences in the behavior of the process in both scales. Realistic circulation mass flows and the respective particle size distributions for the steady-state were obtained. In both scales the tendency towards insufficient oxygen transport from the air to the fuel reactor due to low conversion in the air reactor can be observed. Different behavior could be seen regarding the fuel reactor performance. In the large scale process the fuel gas conversion was limited by fuel gas bypassing the Oxygen Carrier through the bubbles. The small scale fuel reactor on the opposite was able to achieve almost full conversion of the fuel gas. This leads to the question whether a different fuel reactor design could be necessary in a large scale process. It would be advantageous to have smaller bubbles to lower the amount of fuel gas bypassing the bed through the bubbles. This could for example be achieved by the use of internals like heat exchanger tube bundles or baffles and a different gas distributor design.

Oxygen Carrier losses due to attrition and inefficient solids separation could be quantified. The large scale process had a significantly higher OC loss than the small scale process. The main origin of OC loss was different for both scales. In the small scale process OC loss was mainly originating from elutriation in the fuel reactor whereas the large scale process looses most $\mathrm{OC}$ through the air reactor cyclone. In small and large scale most of the attrition was produced in the cyclones for both used sets of attrition constants. Additional cyclones were added to the flowsheet and the simulations showed that in the large scale process a secondary cyclone stage after the air reactor can lower the 
OC losses significantly. Adding a fuel reactor cyclone did not lower OC losses in the large scale. On the contrary in the small scale this measure decreased the OC loss noticeably.

The simulations have shown that solids separation and attrition influence OC losses in a complex manner. Furthermore the simulations suggest that results from measurements in lab or pilot scale can not be directly applied to the large scale. If a small scale CLC process is able to meet the specifications it does not necessarily mean that a scale-up of this design will also meet the same specifications due to the scale-up effect on fluid dynamics. Simulations that do consider this effect and include reaction and attrition descriptions can be very helpful for the prediction of the large scale performance.

\section{ACKNOWLEDGMENTS}

The present work is part of a joint research project of the Institute of Combustion and Power Plant Technology of the University of Stuttgart, the Institute of Energy Systems of the Hamburg University of Technology and the Institute of Solids Process Engineering and Particle Technology of the Hamburg University of Technology. This project received financial support of the German Federal Ministry of Economics and Technology (FKZ 0327844B / CLOCK) with additional funding from BASF SE, EnBW Kraftwerke AG, E.ON Energie AG, Hitachi-Power Europe GmbH, RWE Power AG and Vattenfall Europe Generation AG. The responsibility for the content of this report lies with the authors.

\section{REFERENCES}

1 Lyngfelt A., Leckner B., Mattisson T. (2001) A fluidized-bed combustion process with inherent $\mathrm{CO}_{2}$ separation; application of Chemical-Looping Combustion, Chem. Eng. Sci. 56, 10, 3101-3113.

2 Leion H., Mattisson T., Lyngfelt A. (2009) Use of Ores and Industrial Products as Oxygen Carriers in Chemical-Looping Combustion, Energ. Fuel. 23, 4, 2307-2315.

3 Mattisson T., Lyngfelt A., Cho P. (2001) The use of iron oxide as an Oxygen Carrier in Chemical-Looping Combustion of methane with inherent separation of $\mathrm{CO}_{2}$, Fuel 80, 13, 1953-1962.

4 Adánez J., Cuadrat A., Abad A., Gayán P., Diego L.F. de, García-Labiano F. (2010) Ilmenite Activation during Consecutive Redox Cycles in Chemical-Looping Combustion, Energ. Fuel. 24, 1402-1413.

5 Leion H., Lyngfelt A., Johansson M., Jerndal E., Mattisson T. (2008) The use of ilmenite as an Oxygen Carrier in ChemicalLooping Combustion, Chem. Eng. Res. Des. 86, 9A, 1017-1026.

6 Werther J., Wein J. (1994) Expansion Behavior of Gas Fluidized Beds in the Turbulent Regime, AIChE Symposium Series 301, 90,31-44.

7 Davidson J.F., Schüler B.O.G. (1960) Bubble formation at an orifice in an inviscid liquid, T. Institution Chem. Eng. 38, 335-342.
8 Wen C.Y., Yu Y.H. (1966) A Generalized Method for Predicting the Minimum Fluidization Velocity, AIChE J. 12, 3, 610-612.

9 Kunii D., Levenspiel O. (1991) Fluidization Engineering, Butterworth-Heinemann, Boston.

10 Colakyan M., Levenspiel O. (1984) Elutriation from Fluidized Beds, Powder Technol.38, 223-232.

11 Püttmann A., Hartge E.-U., Werther J. (2008) Modeling of Fluidized Bed Riser-Regenerator Systems, in Circulating Fluidized Bed Technology IX, Werther J., Nowak W., Wirth K.-E., Hartge E.-U. (eds), TuTech Innovation GmbH, Hamburg.

12 Sit S.P., Grace J.R. (1981) Effect of Bubble Interaction on Interphase Mass Transfer in Gas Fluidized Beds, Chem. Eng. Sci.36, 327-335.

13 Sitzmann W., Werther J., Böck W., Emig G. (1985) Modelling of Fluidized Beds - Determination of suitable Kinetics for Complex Reactions, German Chem. Eng. 8, 5, 301-307.

14 Werther J., Hartge E.-U. (2004) A population balance model of the particle inventory in a fluidized-bed reactor/regenerator system, Powder Technol. 148, 113-122.

15 Werther J., Hartge E.-U. (2003) Elutriation and Entrainment, in Handbook of Fluidization and Fluid-Particle Systems, Yang W.C. (ed.), Marcel Dekker, New York.

16 Püttmann A., Hartge E.-U., Werther J. (2010) Application of the Flowsheet Simulation Concept to Fluidized Bed Reactor Modeling. Part 1 - Development of a Fluidized Bed Reactor Simulation Module, Chem. Eng. Process. (to be published).

17 Werther J., Reppenhagen J. (2003) Attrition. Attrition, in Handbook of Fluidization and Fluid-Particle Systems, Yang W.C. (ed.), Marcel Dekker, New York.

18 Merrick D., Highley J. (1974) Particle size reduction and elutriation in a fluidized bed process, AIChE Symposium Series 70, 137, 367-378.

19 Thon A., Püttmann A., Hartge E.-U., Heinrich S., Werther J. (2010) Prediction of Catalyst Attrition in an Industrial Fluidized Bed Plant Based on Lab Scale Attrition Tests, in Fluidization XIII, Kim S.D., Kang Y., Lee J.K., Seo Y.C. (eds), New Paradim in Fluidization Engineering, Engineering Conferences International, New York.

20 Redemann K., Hartge E.-U., Werther J. (2009) A particle population balancing model for a circulating fluidized bed combustion system, Powder Technol. 191, 1-2, 78-90.

21 SolidSim Engineering GmbH (2010) SolidSim, Version 1.2, http://www.solidsim.com/.

22 Hartge E.-U., Pogodda M., Reimers C., Schwier D., Gruhn G., Werther J. (2006) Flowsheet Simulation of Solids Processes, KONA 24, 146-158.

23 Abad A., Adánez J., García-Labiano F., Diego L.F. de, Gayán P., Celaya J. (2007) Mapping of the range of operational conditions for $\mathrm{Cu}-, \mathrm{Fe}-$, and Ni-based Oxygen Carriers in ChemicalLooping Combustion, Chem. Eng. Sci. 62, 1-2, 533-549.

24 García-Labiano F., Adánez J., Diego L.F. de, Gayán P., Abad A. (2006) Effect of Pressure on the Behaviour of Copper-, Iron-, and Nickel-Based Oxygen Carriers for Chemical-Looping Combustion, Energ. Fuel. 20, 26-33.

25 Linderholm C., Mattisson T., Lyngfelt A. (2009) Long-term integrity testing of spray-dried particles in a $10-\mathrm{kW}$ ChemicalLooping combustor using natural gas as fuel, Fuel 88, 11, 20832096.

26 Patience G.S., Bockrath R.E. (2010) Butane oxidation process development in a circulating fluidized bed, Appl. Catal. A: Gen. 376, 1-2, 4-12.

27 Thon A., Werther J. (2010) Attrition resistance of a VPO catalyst, Appl. Catal. A: Gen. 376, 1-2, 56-65. 
28 Noorman S., van Sint Annaland M., Kuipers H. (2007) Packed Bed Reactor Technology for Chemical-Looping Combustion, Ind. Eng. Chem. Res. 46, 12, 4212-4220.

29 Pröll T., Kolbitsch P., Bolhar-Nordenkampf J., Hofbauer H. (2009) A Novel Dual Circulating Fluidized Bed System for Chemical Looping Processes, AIChE J. 55, 12, 3255-3266.

30 Guo Q., Werther J., Hartge E.-U. (2004) The influence of the distributor pressure drop on the hydrodynamics of a circulating fluidized bed, in Fluidization XI, Arena U., Chirone R., Micchio M., Salatino P. (eds), ECI, New York.

31 Muschelknautz E., Greif V., Trefz M. (2006) Zyklone zur Abscheidung von Feststoffen aus Gasen, in VDI-Wärmeatlas, 10th ed., VDI Gesellschaft Verfahrenstechnik und Ingenieurwesen V.D.I. (ed.), Springer-Verlag, Berlin, Heidelberg.
32 Zhu J. (2005) Circulating Fluidized Beds - Recent Developments and Research Requirements in the near Future, in Circulating Fluidized Bed Technology VIII, Cen K. (ed.), International Academic Publishers / World Publishing Corporation, Beijing.

33 Werther J. (1980) Modeling and Scale-up of Industrial Fluidized-Bed Reactors, Chem.Eng. Sci. 35, 1-2, 372-379.

34 Werther J. (1992) Scale-up Modeling for Fluidized-Bed Reactors, Chem. Eng. Sci. 47, 9-11, 2457-2462.

Final manuscript received in November 2010 Published online in April 2011 